\title{
Characterization of Nano-Silica Local Metakaolin Based-Geopolymer: Microstructure and Mechanical Properties
}

\author{
Zeineb Zidi' ${ }^{1}$, Mounir Ltifi'i2, ${ }^{2}$ Idrees Zafar ${ }^{2}$ \\ ${ }^{1}$ Laboratory of Physics of Materials and Nanomaterials Applied to Environment (LaPhyMNE), Faculty of Sciences of Gabes, Gabes \\ University, Gabes, Tunisia \\ ${ }^{2}$ Department of Civil Engineering, College of Engineering, Al Imam Mohammad Ibn Saud Islamic University, Riyadh, KSA \\ ${ }^{3}$ Department of Civil engineering, National Engineering School of Gabes, Gabes University, Gabes, Tunisia \\ Email: mounir.ltifi@gmail.com
}

How to cite this paper: Zidi, Z., Ltifi, M. and Zafar, I. (2020) Characterization of Nano-Silica Local Metakaolin Based-Geopolymer: Microstructure and Mechanical Properties. Open Journal of Civil Engineering, 10, 143-161.

https://doi.org/10.4236/ojce.2020.102013

Received: May 19, 2020

Accepted: June 7, 2020

Published: June 10, 2020

Copyright (c) 2020 by author(s) and Scientific Research Publishing Inc. This work is licensed under the Creative Commons Attribution International License (CC BY 4.0).

http://creativecommons.org/licenses/by/4.0/

\begin{abstract}
The current study focused on the utilization of local clay for synthesis and characterization of meta-kaolin based geopolymers with and without nano-silica. The control geopolymers, for a compressive strength of $30 \mathrm{MPa}$, were optimized by using Liquid/Solid ratio of $0.55, \mathrm{NaOH}$ concentration of $10 \mathrm{M}$ and curing at $80^{\circ} \mathrm{C}$. The nano silica was added in an extended range of $1 \%, 2 \%, 3 \%, 5 \%, 7 \%$ and $10 \%$. The synthesized nano-silica metakaolin based geopolymers was investigated by using compressive strength, XRD, XRF, FTIR, SEM, MIP, TG, UV/VIS spectroscopy, in addition to density, water absorption and initial setting times. The results indicated an increase in the compressive strength value with the incorporation of nano-silica in geopolymer mixes until the optimum percentage of $5 \%$, while the $10 \%$ addition of nano-silica decreased the compressive strength by $5 \%$ as compared to the control geopolymer. The increase in the compressive strength was accredited to the increase in the content of N-A-S-H gel and the amorphous structure as shown by XRD and FTIR analysis. In addition, the optical transmittance analysis, MIP and SEM scans along with the results of density and water absorption have clearly shown the densification of the matrix formed for the optimal percentage of nano-silica. However, the initial setting time was found to reduce substantially with increase of nano-silica content. Moreover, the TG results have shown the $5 \%$ nano-added geopolymers to have greater thermal stability as compared to reference geopolymers. Finally, the adopted methodology in this research has shown that 5\% nano-silica, is the optimal result for the synthesis and the production of local meta kaolin based geopolymer,
\end{abstract}


with regard to the improvement of physical properties, micro structure and compressive strength.

\section{Keywords}

Geopolymer, Nano-SiO ${ }_{2}$, Local-Metakaolin, Mechanical Properties, Microstructure Properties

\section{Introduction}

Geopolymers, in the last few decades, have shown a significant potential to be used as a cementitious material. Along with other properties, the contribution of geopolymers in reducing the environmental footprints of carbon dioxide by replacing cement appears quite appealing and significant. The basic elements required to produce the geopolymer include the source material containing the aluminum and silicon, and an alkaline solution to start the polymerization. Various source materials such as fly ash, biomass bottom ash, slag, silica fume and natural clays have been used for the synthesis of geopolymers. Metakaolin based-geo-polymers have recently gained attention of many researchers due to their unique properties such as rapid compressive strength development, lower thermal conductivity and better resistance to acid as compared to normal cement concrete [1]. However, the properties of the synthesized geopolymer depend significantly on the synthesis parameters: solvent type, source materials, mixing proportions and curing conditions [2] [3] [4] [5]. In this regard, the optimization of the synthesis parameters in relation to the material used appears to be one of the essential steps. In addition, it has been shown that the use of nanotechnologies is very beneficial in various applications due to their excellent physicochemical properties. Several researchers have studied the effect of different types of nano-oxides (nano-kaolin, nano-silica, nano-alumina, carbon nanotubes) on fresh and hardened geopolymer properties and reported that the introduction of nanoparticles in the geopolymer mix improves the mechanical and the microstructure properties [6] [7]. Nano-silica being one of the most commonly used nano material has shown high potential to enhance the properties of different materials [8] [9]. Indeed, the amorphous structure and the high specific surface of nano-silica are expected to produce denser geopolymer than those with traditional additives. Due to their size, nanoparticles can be easily dispersed in the alkaline solution, generating a large number of nucleation sites and resulting in a more homogeneous and dense network. Moreover, the particles size and the properties of the nano-silica strongly depend on the synthesis method [10] [11]. The sol-gel method has been used in many applications due to its advantage of providing different size particles [12] [13]. Various attempts have been made in the past few years to use the nano-silica for synthesis of geopolymers [14] [15]. Khater [14] has shown that the incorporation of nano-silica im- 
proves the geo-polymerization reaction, by the increase of the nucleation sites of $\mathrm{N}-\mathrm{A}-\mathrm{S}-\mathrm{H}$ and C-S-H. An improvement of about $32 \%$ was reported in the compressive strength for a mortar containing $2.5 \%$ nano-silica [16]. Moreover, Phoo-Negernham et al. [17] have noted an improvement of about $31 \%$ in the compressive strength, $44 \%$ in flexure strength and more than $70 \%$ in elasticity, for a geopolymer reinforced by $2 \%$ of nano-silica. In addition, Gao et al. [15] have obtained an increase in the flexure strength from 12 to $15 \mathrm{MPa}$ for geopolymer mixed with $1 \%$ of nano-silica. It was also noticed that the viscosity of the fresh paste of geopolymer decreased with the increase of the nano-silica amount [15]. While most of the cited works agreed that the addition of nano-silica particles generally improved the properties of synthesized geopolymers, however, the optimized percentage of nano-silica differed due to various experimental factors i.e. the method of dispersion of nano-silica, source of local meta-kaolin, the liquid/solid ratio, and the molarity of alkaline solution along with curing temperature.

In the light of above literature review, the present work was carried out to optimize the synthesis of geopolymer using local (Tunisian) metakaolin with and without nano-silica addition. The optimization of control geopolymer was done with regard to liquid/solid ratio, the molarity of alkaline solution and curing temperature. In addition, to determine the optimized percentage of nano-silica, the effect of various percentage of nano-silica addition on mechanical and microstructural properties for the local meta kaolin based-geopolymer were studied using X-ray Fluorescence (XRF), X-ray diffraction (XRD), Fourier Transform Infrared spectroscopy (FTIR), Scanning Electron Microscope (SEM), compressive strength, setting time, density, water absorption and UV/VIS/NIR spectroscopy. In addition, the Mercury Intrusion Porosimetry (MIP) and Thermogravimetry (TG) analysis was also done for the control and optimized nano-silica geopolymer.

\section{Materials and Experimental Procedure}

\subsection{Materials}

In this work, natural clay, collected from Medenine (south Tunisia); was used as a base material for the synthesis of the geopolymer mortar. The raw material was crushed and passed through a sieve of $80 \mu \mathrm{m}$ and then calcined at $750^{\circ} \mathrm{C}$ for 4 hours. Finally, the metakaolin was carefully mixed to obtain a homogeneous sample. The chemical composition of metakaolin, determined by X-ray Fluorescence (XRF) consisted mainly of $54.66 \%$ silica oxide and $22.27 \%$ alumina oxide.

Nano-silica was synthesized by sol-gel method according to El Mir [18] protocol. The TEM image (Figure 1) exhibits a uniform spherical particle with sizes ranging between 50 and $100 \mathrm{~nm}$. The physical properties of nano-silica are summarized in Table 1. 


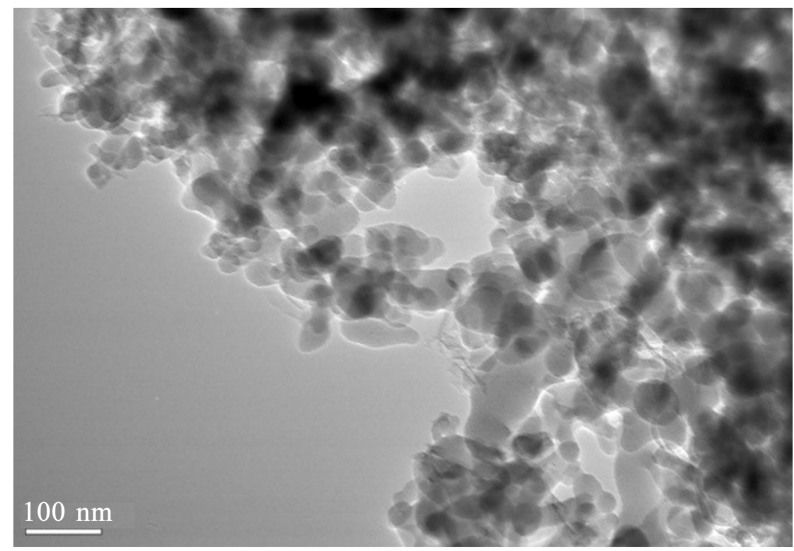

Figure 1. TEM of nano-silica.

Table 1. The properties of nano silica.

\begin{tabular}{ccccccc}
\hline Properties & Phase & Form & Size $(\mathrm{nm})$ & Density $\left(\mathrm{g} / \mathrm{cm}^{3}\right)$ & Porosity & Content of $\mathrm{SiO}_{2}$ \\
\hline Content & Non-crystal & sphere & $14-20$ & 0.17 & Nonporous & $99.9 \%$ \\
\hline
\end{tabular}

\subsection{Optimization Approach for the Synthesis of the Control Geopolymer}

The optimization for the synthesis of geopolymer was based on the effect of three critical synthesis parameters: liquid to solid ratio L/S, concentration of sodium hydroxide and curing temperature, on the compressive strength of the hardened geopolymer. The details of the test matrix for the synthesis of geopolymer are given in Table 2. In addition, the flowchart describing the optimizing of the geopolymer synthesis under different experimental conditions is shown in Figure 2. Compressive strength was considered as the control parameter for selection of the optimized test parameters. For each formulation, the compressive strength was determined after 7, 14 and 28 days using a Tonic-Technik Testing Machine moving at a constant cross-head displacement of $0.24 \mathrm{~N} / \mathrm{S}$ according to the standard procedure of ASTM D1633-00 [19]. The compressive tests were performed on three samples for each composition and the average value of three compressive strengths was considered.

\subsubsection{Activator Liquid to Source Metakaolin Ratio}

The 28 days' compressive strength of hardened geopolymer paste with various L/S ratios is presented in Figure 6. The values of compressive strength were found to be $19 \mathrm{MPa}, 30 \mathrm{MPa}, 15 \mathrm{MPa}$ and $7 \mathrm{MPa}$ for L/S ratio of $0.5,0.55,0.6$, and 0.65 respectively. It was observed that the optimum value of $\mathrm{L} / \mathrm{S}$ ratio was found to be 0.55 with regard to the highest value of 28 -day compressive strength.

\subsection{2. $\mathrm{NaOH}$ Concentration}

The results showed that the compressive strength increased as the concentration of $\mathrm{Na}(\mathrm{OH})$ is increased from $6 \mathrm{M}$ to $10 \mathrm{M}$. The 28 days' compressive strength for $6,8,10 \mathrm{M}$ was found to be $12.5,23$ and $30 \mathrm{MPa}$ respectively. It is also important 


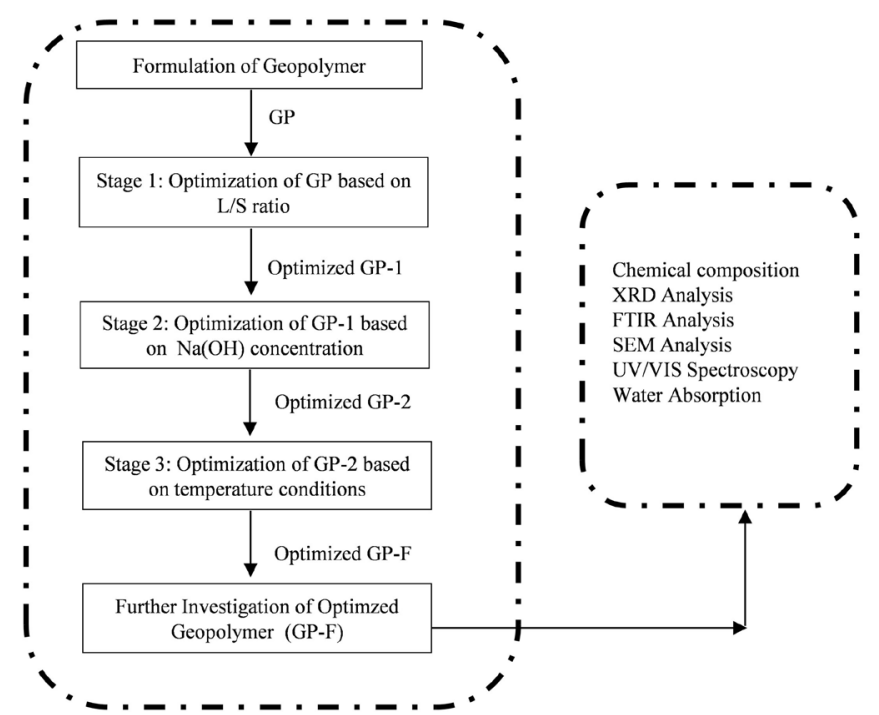

Figure 2. Flowchart describing the optimization of the geopolymer synthesis and characterization of optimized geopolymer.

Table 2. Test matrix for the optimization of synthesis factors for geopolymer.

\begin{tabular}{|c|c|c|c|c|}
\hline \multirow{2}{*}{ Series } & \multirow{2}{*}{ Test parameter } & \multicolumn{3}{|c|}{ Mix proportion } \\
\hline & & $\mathrm{NaOH}(\mathrm{M})$ & $\mathrm{L} / \mathrm{S}$ & Temperature $\left({ }^{\circ} \mathrm{C}\right)$ \\
\hline \multirow{4}{*}{1} & \multirow{4}{*}{$\begin{array}{c}\text { Activator liquid to } \\
\text { source metakaolin ratios }(\mathrm{L} / \mathrm{S})\end{array}$} & 10 & 0.50 & 80 \\
\hline & & 10 & 0.55 & 80 \\
\hline & & 10 & 0.60 & 80 \\
\hline & & 10 & 0.65 & 80 \\
\hline \multirow{3}{*}{2} & \multirow{3}{*}{$\mathrm{NaOH}$ concentration } & 6 & 0.55 & 80 \\
\hline & & 8 & 0.55 & 80 \\
\hline & & 10 & 0.55 & 80 \\
\hline \multirow{5}{*}{3} & \multirow{5}{*}{ Curing temperature } & 10 & 0.55 & 20 \\
\hline & & 10 & 0.55 & 40 \\
\hline & & 10 & 0.55 & 60 \\
\hline & & 10 & 0.55 & 80 \\
\hline & & 10 & 0.55 & 90 \\
\hline
\end{tabular}

to note that, at each test time ( 7,14 and 28 days) the samples which have the highest concentration of $\mathrm{Na}(\mathrm{OH})$ possessed the highest value of strength.

\subsubsection{Curing Temperature}

The compressive strength of 28 days hardened metakaolin-based geopolymer at different temperatures of $20^{\circ} \mathrm{C}, 40^{\circ} \mathrm{C}, 60^{\circ} \mathrm{C}, 80^{\circ} \mathrm{C}$ and $90^{\circ} \mathrm{C}$ for $24 \mathrm{~h}$ were found to be $19,22,25,30$ and $26.5 \mathrm{MPa}$ respectively. The results showed that the compressive strength of the sample carried out at room temperature was $19 \mathrm{MPa}$. However, when the curing temperature was increased from $20^{\circ} \mathrm{C}$ to $80^{\circ} \mathrm{C}$, the 
compressive strength gradually increased until reaching its optimum value of 30 $\mathrm{MPa}$ at $80^{\circ} \mathrm{C}$ and decreased for further increase in the curing temperature i.e. $90^{\circ} \mathrm{C}$.

Thus the optimized values with regard to compressive strength for the test parameters i.e. $\mathrm{L} / \mathrm{S}$ ratio, $\mathrm{NaOH}$ concentration and curing temperature were found to be $0.55 \mathrm{M}, 10 \mathrm{M}$ and $80^{\circ} \mathrm{C}$ respectively. All the geopolymers with or without nano-silica addition in the current were synthesized using these optimized values along with some considerations during the synthesis procedures.

\subsection{Mix Proportion for Geopolymers Mixes}

Firstly, the alkaline activator solution was prepared by mixing sodium hydroxide solution (SS) $\left(\mathrm{SiO}_{2}: 26.5 \%, \mathrm{Na}_{2} \mathrm{O}: 10.6 \%\right.$ and $\mathrm{H}_{2} \mathrm{O}: 62.9 \%$ modulus $\mathrm{M}$ $=\% \mathrm{SiO}_{2} / \% \mathrm{Na}_{2} \mathrm{O}=2.5$ ) and sodium silicate solution $(\mathrm{SH})$ (ultrapure water and pellets of $\mathrm{NaOH}$ with $10 \mathrm{M}$ concentration) with $\mathrm{SS} / \mathrm{SH}$ ratio of 2. Secondly, the different amounts of nano-silica $(1 \%, 2 \%, 3 \%, 5 \%, 7 \%$ and $10 \%$ by weight) were dispersed in this alkaline solution under magnetic stirring for 15 minutes to avoid the agglomeration. Then, the metakaolin was added to the solution, for the different mixtures prepared with a constant liquid/solid ratio (L/S) of 0.55 . The fresh paste obtained was casted into $30 \times 60 \mathrm{~mm}$ cylindrical molds for the compressive strength tests. Finally, the samples were vibrated to remove air bubbles and allowed to cure at $80^{\circ} \mathrm{C}$ for 24 hours. The different mixtures prepared and investigated in this work are summarized in Table 3.

\subsection{Characterization of Geopolymer Mixes}

The setting time measurement of fresh mortars was performed by Vicat needle apparatus according to EN 196-3 2008. For all samples, the compressive strength test was determined after 28 days according to the standard procedure of ASTM D1633-00 [19]. The values of compressive strength correspond to the average of three measurements for each mixture. After the compression tests, the samples were crushed, washed with acetone to stop the reaction and dried at $60^{\circ} \mathrm{C}$ and then, used for the microstructure analysis. X-ray diffraction (XRD) (Bruker D5005) was used to determine the crystalline phase of the ground powders using

Table 3. Composition of the different mixtures studied.

\begin{tabular}{cccccc}
\hline $\mathrm{Mix}$ & $\mathrm{MK}(\mathrm{g})$ & $\mathrm{Nano} \mathrm{SiO}_{2}(\mathrm{~g})$ & $\mathrm{NaOH}(\mathrm{g})$ & $\mathrm{NaSO}_{3}(\mathrm{~g})$ & Water $(\mathrm{g})$ \\
\hline $\mathrm{S} 0$ & 20 & 0 & 1.04 & 7.32 & 2.61 \\
$\mathrm{~S} 1$ & 19.8 & 0.2 & 1.04 & 7.32 & 2.61 \\
$\mathrm{~S} 2$ & 19.6 & 0.4 & 1.04 & 7.32 & 2.61 \\
$\mathrm{~S} 3$ & 19.4 & 0.6 & 1.04 & 7.32 & 2.61 \\
$\mathrm{~S} 5$ & 19 & 1.0 & 1.04 & 7.32 & 2.61 \\
$\mathrm{~S} 7$ & 18.6 & 1.4 & 1.04 & 7.32 & 2.61 \\
$\mathrm{~S} 10$ & 18 & 2 & 1.04 & 7.32 & 2.61 \\
\hline
\end{tabular}


a Co Ka source (1.78901 $\AA$ wavelength), the $2 \theta$ range is between $15^{\circ}$ and $80^{\circ}$, with $0.02^{\circ} 2 \theta$ steps. Scanning electron microscopy (SEM Philips XL 30), FT-IR spectra (Perkin-Elmer 180) with a resolution of $4 \mathrm{~cm}^{-1}$ ranging from 400 to 4000 $\mathrm{cm}^{-1}$, were used to identify the morphology and microstructural properties of geopolymer mortars, with and without nano-silica addition. The effect of nano-silica on optical properties was performed by UV-VIS-NIR spectroscopy (Schimadzu UV-3101 PC spectrophotometer with integrating sphere), in the spectral range from 200 to $1800 \mathrm{~nm}$. Furthermore, the water absorption tests were carried out in two steps: samples were dried at $105^{\circ} \mathrm{C}$ for 24 hours $\left(m_{1}\right)$, then they were immersed in water for 24 hours $\left(m_{2}\right)$ (ASTM C140). The water absorption percentage and the density were determined according to the following formulas shown in Equations (1) and (2) respectively:

$$
\begin{gathered}
\operatorname{Absorption}(\%)=\left[\frac{m_{1}-m_{2}}{m_{1}}\right] \times 100 \\
D=\frac{m}{\pi\left(\frac{d}{2}\right)^{2}} e^{\left(\mathrm{g} / \mathrm{cm}^{3}\right)}
\end{gathered}
$$

where:

$$
\begin{aligned}
& m=\text { Weight of the sample }(\mathrm{g}) \\
& e=\text { Thickness of the sample }(\mathrm{cm}) \\
& d=\text { Diameter of the sample }(\mathrm{cm})
\end{aligned}
$$

In addition, the mercury intrusion porosimetry was carried out by AUTOPORE IV 9500 from Micromeritics for the reference and optimized nano-silica added geopolymer. Thermo-gravimetric analysis is normally used to monitor the mass of the sample over time with change in temperature at constant rate. The TG analysis for the reference and optimized nano-silica added geopolymers was carried out by a STA6000 thermal analyzer with a temperature range of $25^{\circ} \mathrm{C}$ to $450^{\circ} \mathrm{C}$ and a constant rate of $5^{\circ} \mathrm{C} / \mathrm{min}$.

\section{Results and Discussion}

\subsection{Setting Times}

The initial setting time of geopolymer pastes having different amounts of nano- $\mathrm{SiO}_{2}$ are plotted in Figure 3. When the nano $\mathrm{SiO}_{2}$ content is increased up to $5 \%$ in the fresh geopolymer pastes, the setting time is decreased gradually from $360 \mathrm{~min}$ to $45 \mathrm{~min}$, but it can still be practically acceptable. This reduction is attributed to the acceleration of the chemical reaction at early ages which is related to the easy connection between the unsaturated Si-O and Si bonds of nano-silica atom located in the surface and the free ions of Metakaolin. The decrease can also be attributed to the increase of the viscosity of the paste, due to acceleration of water adsorption by the high specific surface of nano-silica. Beyond the 5\% addition of nano-silica, it was almost impossible to measure the value of the initial setting time of pastes. Indeed, the increase in the percentage of nanoparticles 


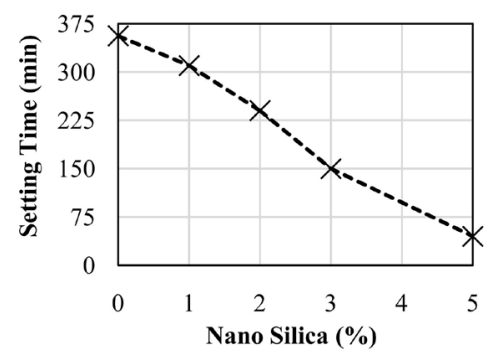

Figure 3. Initial setting time of geopolymer mixed by nano-silica.

in mixtures $(>5 \%$, more particularly that of $10 \%)$, makes the mix very firm. It seems that the high reactivity of the nano-silica, by the surface effect, immobilizes the water which affects its viscosity [20].

\subsection{Mechanical Properties}

The effects of nano-silica addition on 28 days' compressive strength of geopolymer mortar are presented in Figure 4. It was observed that the compressive strength increased as the percentage of nano-silica increased until 5\%. This is can be attributed to the enhancement of the geopolymer microstructure. However, it was also noticed that the further increase in the nano-silica percentage decreased the compressive strength values. Nevertheless, it must be stated that while the resistance decreased at $7 \%$ as compared to the optimum value i.e. 42 $\mathrm{MPa}$ at 5\%, it still remained higher than that of control geopolymer. Addition of $10 \%$ nano-silica had a negative effect on the development of compressive strength, where it decreased by $5 \%$ when compared to that of the control geopolymer. This decrease is strongly related to the observations noted above concerning the significant reduction in setting time. Indeed, the increase in the percentage of nanoparticles can accelerate the kinetics of the geo-polymerization reaction, but it is likely to increase the agglomeration of these nanoparticles, which can disturb the microstructural organization of the geopolymer.

Several researchers have studied the effect of nano-silica on the compressive strength of synthesized geopolymers. Lo et al. have reported that the best mechanical resistance of geopolymer was observed in mortars containing $2 \%$ nano-silica [20]. Also, Phoo-Ngernkham et al. [17] showed that the incorporation of $1 \%$ to $2 \%$ NS was favorable to improve the mechanical resistance of geopolymer as compared to higher percentages. Deb et al. also studied the effect of nano-silica variation on the strength of alkali activated geoplymer and found the optimal percentage to be around $2 \%$ for the studied conditions [21]. It was observed that although the optimal percentage of the nano-silica for most of the past researchers was found to be around $2 \%$ while, the highest compressive strength among all the nano-silica percentages used for the current study was at $5 \%$ addition of nano-silica. 5\% nano-silica addition has shown an improvement of $40 \%$ in compressive strength as compared to the control geopolymer while retaining the other geo-polymerization reaction parameters as constant. 


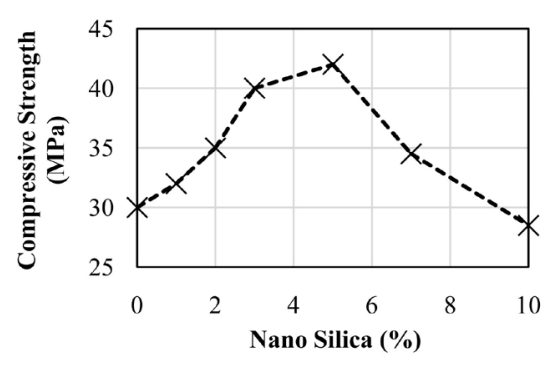

Figure 4. Compressive strength of geopolymer mixes.

\subsection{Structural Characterization}

XRD pattern of 28-day hardened geo-polymer samples admixed with various amounts of nano-silica is shown in Figure 5.

From XRD patterns, it is evident that some dissolvable minerals such as quartz and Mullite have remained in all the products. In general, XRD patterns of geopolymers have a diffuse hump at about $26^{\circ}-30^{\circ}$ with relatively smaller intensities indicates that the geopolymer material has almost complete amorphous structure. According to Figure 5 the intense peak is at $26.5^{\circ}$ in $2 \theta$ and corresponds to quartz while at $28^{\circ}$ it could be considered a broad hump that would correspond to the vitreous phase of the geopolymer. It was also noted that an increase in the percentage of nano-silica for the geo-polymer mixes induced a gradual increase in this XRD peak intensity. In addition, a slight shift of this peak was also seen when the nano-silica content increased from $1 \%$ to $5 \%$. This can be explained by the improvement of the content of N-A-S-H gel, which is probably, attributed to the enhancement of the interaction of the dissolved species. On the other hand, the incorporation of $10 \%$ nanoparticles presents a negative effect on microstructural properties of the geo-polymer, indicated by a shift to lower angle due to the agglomeration, which hinders the reaction.

Furthermore, from these diffractograms a clear increase in the intensity of the $\mathrm{SiO}_{2}$ peak with addition of nano-silica is visible, which indicates the existence of non-reacted nano-silica in geo-polymerization reaction. These observations confirm the same tendencies noted above regarding setting time and compressive strength. Therefore, the positive effect of nano-silica addition on the metakaolin based geo-polymer seems to be around 5\%. Beyond this value, and particularly for a percentage of $10 \%$, the negative effect is highlighted, by the decreasing of compression strength and illustrated by XRD analysis. These results are in agreement with those reported by Assaedi et al. [22] and Khater [14].

\subsection{Fourier Transform Infrared Spectroscopy (FTIR)}

Figure 6 shows FTIR spectra of alkali-activated geopolymer containing different amounts of nano-silica. The spectrum of control sample exhibits the principal bands of geopolymer: an intense and sharp band at $1000 \mathrm{~cm}^{-1}$, attributed to asymmetric strength $\mathrm{T}-\mathrm{O}-\mathrm{Si}(\mathrm{T}=\mathrm{Si}$ or $\mathrm{Al})$ bond, a weak band in the region of $1435 \mathrm{~cm}^{-1}$ attributed to the presence of $\mathrm{Na}_{2} \mathrm{CO}_{3}$ sodium carbonate, a binding 


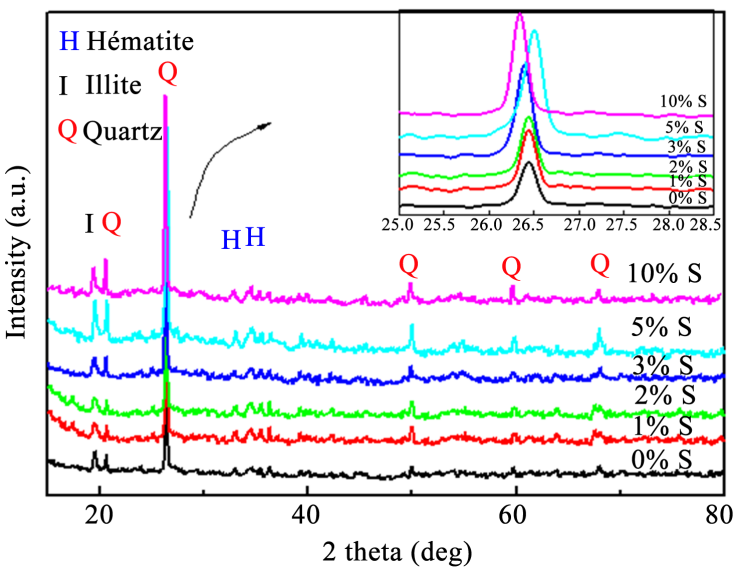

Figure 5. Compressive XRD patterns of geopolymers [Main diffraction peaks are indexed according to the JCPDS files Q: Quartz (04-008-7651), I: Illite (04-016-2976), H: Hematite (04-002-4944)].

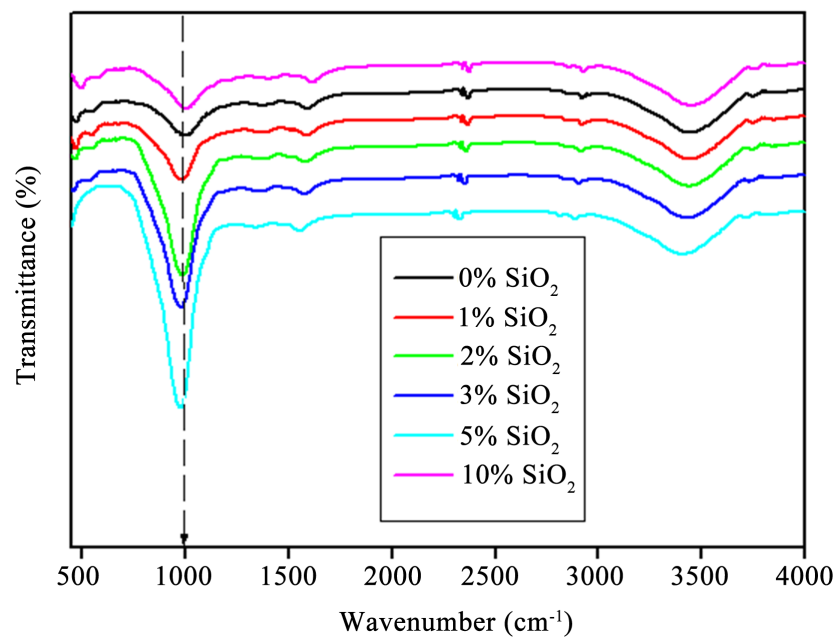

Figure 6. FTIR spectra of geopolymers with different contents of nano-silica.

vibration band located in the region of $469 \mathrm{~cm}^{-1}$ related to Si-O-Si bond and two water molecules bands located at $3550 \mathrm{~cm}^{-1}$ and at $1649 \mathrm{~cm}^{-1}$. The incorporation of the nano-silica increases gradually the intensity of the asymmetric T-O-Si band. It can be attributed to the enhancement of the nano-silica effect in geo-polymerization reaction, which offers more nucleation sites of the N-A-S-H gel, and therefore increases the propagation of the molecular chains and improves the geopolymer network formation. Also, it is very important to mention the shift of the T-O-Si band position by $12 \mathrm{~cm}^{-1}$ to lower wavenumber. This indicates the interaction of the reacted particles and reflects an enhancement in the geopolymeric reaction. However, the addition of nano-silica over $5 \%$ hinders the formation of geopolymer gel indicated by the decrease of the N-A-S-H band, which is due to the agglomeration of the nanoparticles. The same result was observed in the XRD patterns. These results are in agreement with those found by Lo et al., 2017 [20]. 


\subsection{Chemical Composition (RXF)}

Table 4 presents the chemical composition of alkali-activated geo-polymers with and without nano- $\mathrm{SiO}_{2}$. The results showed an increase in the $\mathrm{SiO}_{2} / \mathrm{Al}_{2} \mathrm{O}_{3}$, $\mathrm{SiO}_{2} / \mathrm{NaO}_{2}$ and $\mathrm{Al}_{2} \mathrm{O}_{3} / \mathrm{Na}_{2} \mathrm{O}$ ratio when the nano-silica content is increased from $0 \%$ to $10 \%$. Aughenbaugh et al. [23] reported the optimum range of $\mathrm{SiO}_{2} / \mathrm{Al}_{2} \mathrm{O}_{3}$, $\mathrm{SiO}_{2} / \mathrm{NaO}_{2}$ and $\mathrm{Al}_{2} \mathrm{O}_{3} / \mathrm{Na}_{2} \mathrm{O}$ ratio for the metakaolin based geopolymer from 1.87 to $4.0,4.0$ to 3.125 and 1.0 to 1.15 respectively. In addition, Raphaelle [24] has plotted the contour showing the effect of $\mathrm{SiO}_{2} / \mathrm{Al}_{2} \mathrm{O}_{3}, \mathrm{H}_{2} \mathrm{O} / \mathrm{NaO}_{2}$ and $\mathrm{Al}_{2} \mathrm{O}_{3} / \mathrm{Na}_{2} \mathrm{O}$ ratio on the compressive strength of synthesized geopolymers and reported the optimum ranges of $\mathrm{SiO}_{2} / \mathrm{Al}_{2} \mathrm{O}_{3}$ and $\mathrm{Al}_{2} \mathrm{O}_{3} / \mathrm{Na}_{2} \mathrm{O}$ ratio for $80 \mathrm{MPa}$ to be 3.6 to 3.8 and 0.84 to 1.0 respectively. It was noticed that the values for the respective ratios found in the current study are on the higher side as compared to the ones reported in the literature but still the difference between them is not significant [23] [24]. It should be noted that in various studies the values of the optimum ratios had varied with the experimental conditions used for optimizing the synthesis of geopolymers in addition to the chemical composition of the source metakaolin. Furthermore, the $\mathrm{pH}$ of all prepared samples was also presented in $\mathrm{Ta}$ ble 4. Chindaprasirt et al. [25] have reported that the N-A-S-H gel became stable at $\mathrm{pH}$ ranging from 9 to 12. In this regard, it can be inferred that all the gels for the prepared mixes were stable; however, depending upon the local conditions available for the geo-polymerization, the further reaction will precede leading to different mechanical and physical properties with varied percentage of nano-silica.

\subsection{Optical Transmission}

Transmission spectroscopy is an effective technique to investigate the optical properties of geopolymers. By using the Dahm model [26], for any wavelength and thickness, the absorption, the transmission and the reflection are related as shown in Equation (3):

$$
A(T, R)=\frac{(1-R)^{2}-T^{2}}{R}
$$

For opaque specimen, the transmission is negligible therefore, Equation (4) governs:

$$
A(0, R)=\frac{(1-R)^{2}}{R}
$$

Table 4. Chemical composition of geopolymer mortar from XRF technique.

\begin{tabular}{ccccc}
\hline $\mathrm{Mix}$ & $\mathrm{SiO}_{2} / \mathrm{Al}_{2} \mathrm{O}_{3}$ & $\mathrm{SiO}_{2} / \mathrm{NaO}_{2}$ & $\mathrm{Al}_{2} \mathrm{O}_{3} / \mathrm{Na}_{2} \mathrm{O}$ & $\mathrm{pH}$ \\
\hline $\mathrm{S} 0$ & 4.40 & 9.85 & 2.24 & 10.28 \\
$\mathrm{~S} 2$ & 4.64 & 10.57 & 2.28 & 10.16 \\
$\mathrm{~S} 5$ & 4.98 & 11.25 & 2.26 & 10.14 \\
$\mathrm{~S} 10$ & 5.51 & 12.39 & 2.25 & 10.76 \\
\hline
\end{tabular}


The transmission spectra of geopolymers with various amounts of nano $\mathrm{SiO}_{2}$ (from $1 \%$ to $10 \%$ ) in the UV/VIS/NIR range are presented in Figure 7. In this figure, three principal zones of transmission are depicted. The first zone, from 200 to $530 \mathrm{~nm}$, presents an intense transmission, about $77 \%$ for pure geopolymer, while the increase in nano-silica content up to $5 \%$ caused the optical transmission to decrease by $17 \%$. In the second zone, between 530 and $1000 \mathrm{~nm}$, the curves show a decrease of $50 \%$, this can be due to the fundamental absorption. On the other hand, the average transmission fractions are reduced by $11 \%$ compared to control sample. In both zones, the sample with 5\% nano-silica possessed the lowest transmission fraction compared to the control mixes. Finally, for wavelengths beyond $1000 \mathrm{~nm}$ the transmission fraction vanished, it can attribute to the highest reflectance measured. The variation was due to the pore fraction generated during the synthesizing process. The experimental results indicated that the geopolymer having nano-silica had a dense network. Gasca-Tirado et al. [27] show that the porosity is the principal factor to modify the amount of light transmission. Thus, it can be seen that the decrease of the transmission with the increase of nano-silica amount is related to the filling of the pore resulting in densification of the microstructure for the synthesized geopolymer [28] [29]. The results of optical transmission are in agreement with the results of compressive strength, XRD and FTIR analysis reported in the above sections.

\subsection{Water Absorption}

The water absorption and the density of the hardened geopolymer paste are shown in Figure 8. The curve shows that the density increased gradually when the nano-silica incorporation increased up to $5 \%$ and then decreased for $10 \%$ addition. While the opposite behavior was measured for the water absorption capacity of the synthesized geopolymer i.e. the water absorption curve gradually

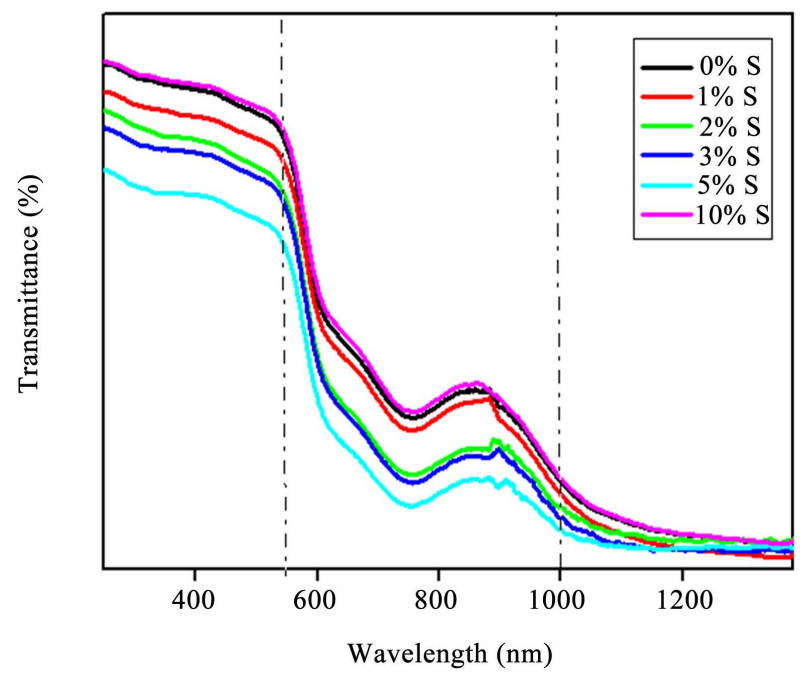

Figure 7. Effect of nano $\mathrm{SiO}_{2}$ on transmittance. 


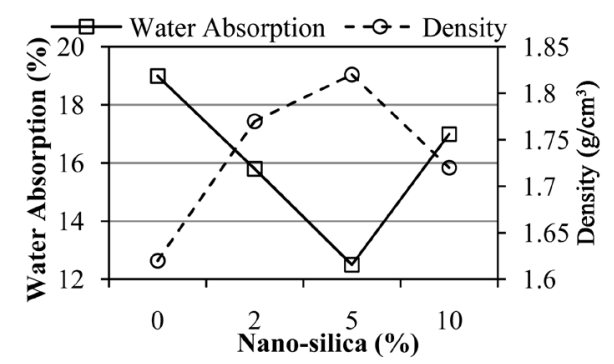

Figure 8. Effect of nano $\mathrm{SiO}_{2}$ on density and water absorption of geopolymer.

decreased till 5\% and then increased for $10 \%$ of nano-silica. The water absorption values normally present the percentage of defects (pores/cracks) that can be filled with water. Thus, in terms of water absorption results it was observed that the addition of nano-silica until 5\% has resulted in the decrease of pores available to absorb water. This result indicates that the addition of nano-silica up to $5 \%$ improves the properties of the geopolymer structures. Beyond this value, it had a negative effect, which can be attributed to the agglomeration of non-reactive nanoparticles. The results of decrease in density and respective increase in the water absorption with increase in the nano-silica till 5\% complements the results of compressive strength and optical transmittance clearly indicating the improvement in the microstructure. Furthermore, the results of density and water absorption are in agreement with those reported by Assaedi et al. [22].

\subsection{Scanning Electron Microscopy (SEM)}

The SEM scans of geo-polymers having different amounts of nano- $\mathrm{SiO}_{2}$ are shown in Figure 9. It was observed that the incorporation of nano-silica improved the structural homogeneity of the geopolymer. Figure 9 (b) and Figure 9(c) showed the high density of the matrix representing the geopolymers mixed with $2 \%$ and $5 \%$ of nano-silica respectively. Although the quantitative analysis for measuring the exact chemical ratio of the products formed by the incorporation of nano-silica was not done but the uniformity of the matrix and presence of the cracks were observed through SEM scans. Finally, as shown in Figure 9(d), the matrix presents micro-cracks probably not only due to the agglomeration of the nanoparticles but also because of the non-reactivity of a large part of nano-silica which might have caused the decrease in the mechanical properties of geoplomers at higher addition of nano-silica (10\%). Similar findings were reported by other researchers as well Adak et al. [30] and Deb et al. [21].

\subsection{Mercury Intrusion Porosimetry (MIP)}

The pore size distribution for the control and optimized nano-added geopolymers i.e. 5\% of nano silica addition is shown in Figure 10. It was observed that addition of $5 \%$ nano silica has resulted in two different effects on the pore size distribution of control geopolymers. Firstly, a clear reduction in the small sized 


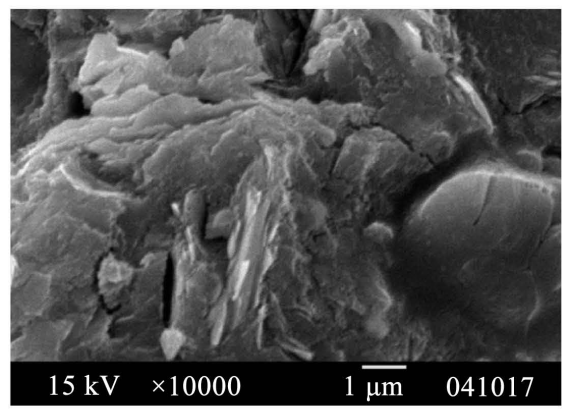

(a)

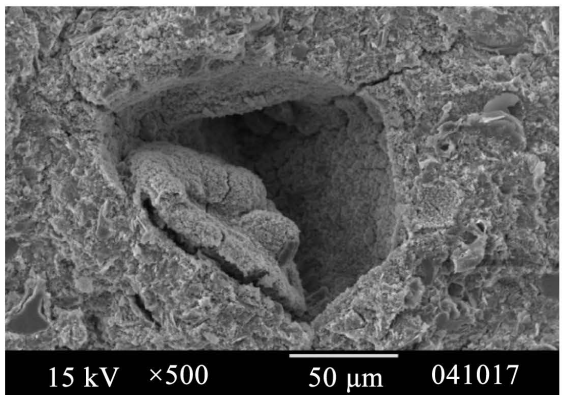

(c)

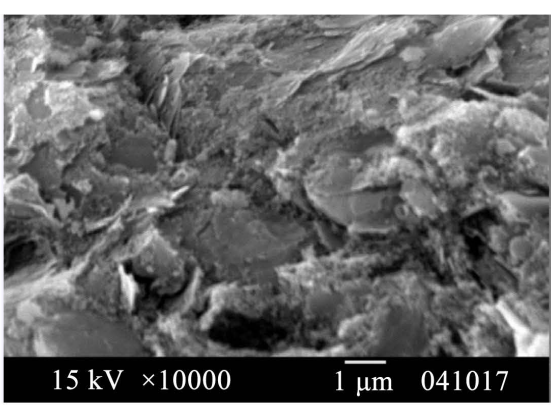

(b)

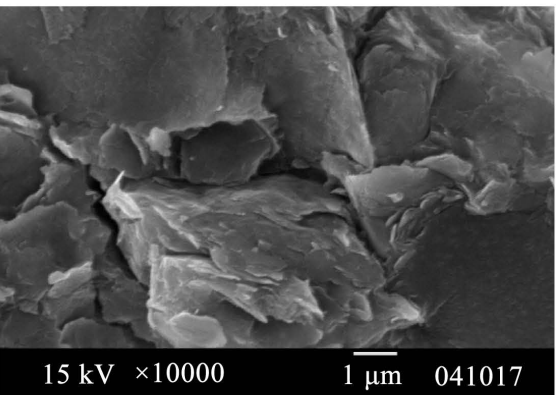

(d)

Figure 9. SEM scans of geopolymers with different amounts of nano- $\mathrm{SiO}_{2}:$ (a) $0 \%$, (b) $2 \%$, (c) $5 \%$ and (d) $10 \%$.

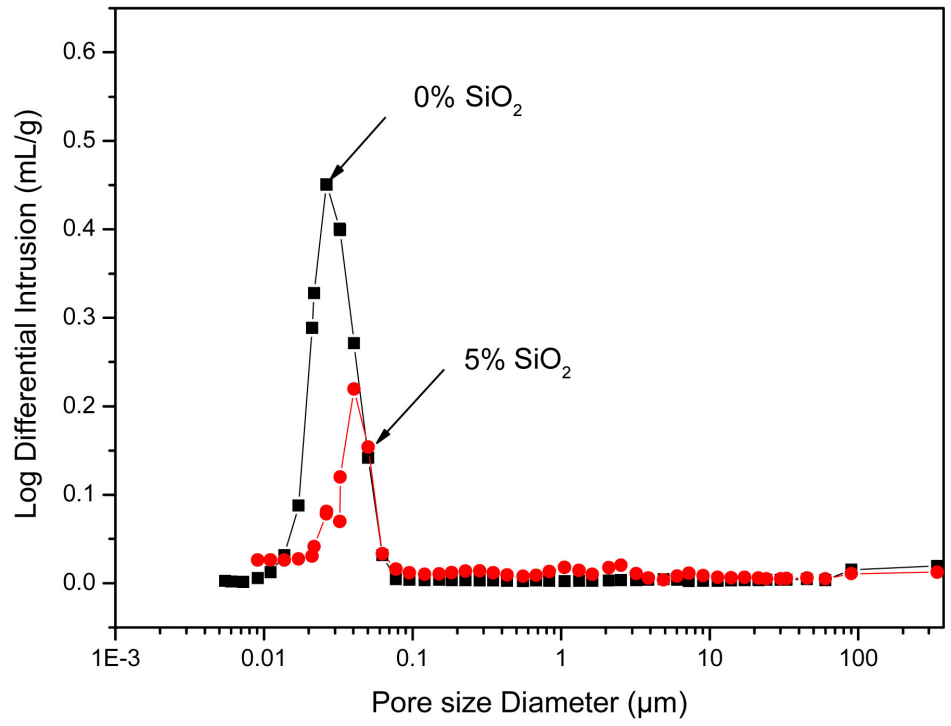

Figure 10. Pore size distribution of control and 5\% nano-added geopolymers.

pores was observed for nano-silica added geopolymers and secondly, it was noticed that there is an increase in the pore size when 5\% nano silica was added. However, the final porosity estimated by the MIP indicated a clear reduction in the porosity values of $5 \%$ nano-added geopolymers as compared to the control sample. The values of porosity for the control and nano-silica added geopolymer were found to be $32.6 \%$ and $22.8 \%$ respectively. 
These results are in line with the results of XRD, FTIR and compressive strength, water absorption and density, which have shown the $5 \%$ nano-silica geopolymers to have the better mechanical and micro-structural properties as compared to other series.

\subsection{Thermogravimetry (TG) Analysis}

The thermo-gravimetric and differential thermo-gravimetric variation of control and 5\% nano-silica geopolymers with temperature is shown in Figure 11. It was shown in Figure 11 that the weight loss between $25^{\circ} \mathrm{C}$ to $70^{\circ} \mathrm{C}$ was on the higher side for the control geopolymer as compared to nano-silica geopolymer while after $70^{\circ} \mathrm{C}$, the slope of the TG curve for $5 \%$ nano-silica geopolymer was steeper as compared to control sample.

At $200^{\circ} \mathrm{C}$, the weight loss was found to be $5.5 \%$ and $8 \%$ for the control and $5 \%$ nano-silica geopolymer respectively. In Figure 11, a significant reduction in the mass was observed in a temperature range of $25^{\circ} \mathrm{C}$ to $200^{\circ} \mathrm{C}$. This decrease can be mainly because of the evaporation of physically adsorbed water. For the same temperature range as shown in Figure 11, the slope of the differential thermo-gravimetric curve for control geopolymer is on the higher side causing the peak to move towards the lower temperature as compared to the peak of nano-silica added geopolymer. The shifting of peak to higher temperature for nano-added silica geopolymers indicates greater thermal stability as compared to control geopolymer. The increase in the thermal stability can be because of the improvement in the pore structure as indicated by the results of MIP and SEM. After $200^{\circ} \mathrm{C}$, the weight loss percentage for the control and nano-silica geopolymers begin to retard because the evaporation of free water had finished and the decomposition of chemically bound water had initiated [31].

\section{Conclusion}

The current study was done to optimize the synthesis of geoplomyer with and without incorporation of nano-silica using a local metakaolin as an aluminosilicate source. Firstly, the control geopolymers were synthesized and optimized based on the experimental parameters i.e. Liquid/Solid ratio, $\mathrm{NaOH}$ concentration and curing temperature, depicting the optimal values to be $0.55,10 \mathrm{M}$ and

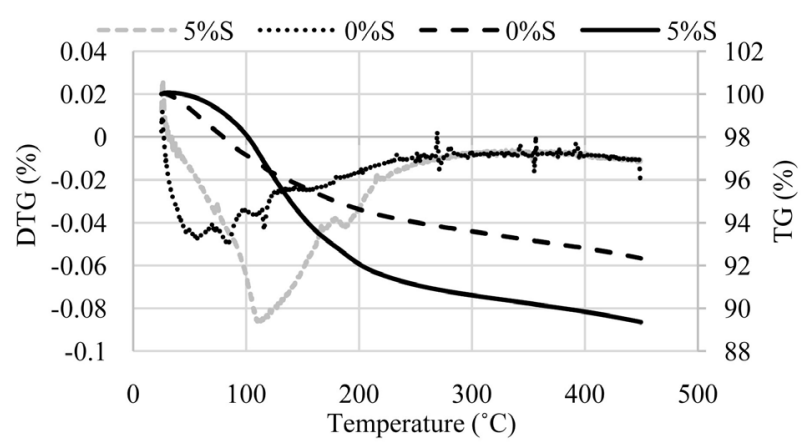

Figure 11. TG/DTG curves for geo-polymers with $0 \%$ and $5 \%$ nano-silica. 
$80^{\circ} \mathrm{C}$ respectively leading to a compressive strength of $30 \mathrm{MPa}$. To optimize the nano-silica percentage for synthesized geopolymer, the fresh, mechanical, optical, structural characteristics along with physical properties of the synthesized geopolymers at various percentages of nano-silica were investigated. The compressive strength of the synthesized geopolymer displayed positive impact with addition of nano-silica until the optimal percentage of 5\%. The increase of $16.7 \%$ and $40 \%$ as compared to the control geopolymers was noticed with addition of $2 \%$ and $5 \%$ of nano-silica respectively, while the $10 \%$ nano-silica decreased the compressive strength by $5 \%$. The increase in the compressive strength was mainly attributed to the increase of $\mathrm{N}-\mathrm{A}-\mathrm{S}-\mathrm{H}$ gel as indicated by the increase of the FTIR intensity of T-O-Si band and the increase of the broadness of the XRD peak. Furthermore, the improvement of the microstructure for the optimum percentage of $5 \%$ was also confirmed by the optical transmittance analysis, MIP and SEM scans showing the increase in the homogeneity and the densification of the matrix. However, it was also noticed that the smaller specific surface of nano-silica has not only increased the density and reduced the water absorption but also has caused the acceleration of the geo-polymerization reaction as the setting time of the synthesized geopolymers substantial decrease by 8 times with $5 \%$ of nano-silica. Moreover, the TG analysis has shown the higher thermal stability for $5 \%$ nano-silica added geopolymers as compared to the control geopolymer. Finally, based on the results of current study, $5 \%$ nano-silica was found to be the optimum percentage for synthesis and the production of local metakaolin based geopolymer showing acceptable mechanical resistance and satisfactory physical and structural properties. Though the study has presented the experimental guideline for synthesis of geopolymers using local clay, however, detailed insights into chemical transformations linked to the geopolymer manufacturing process to develop practical recommendations are to be considered.

\section{Conflicts of Interest}

The authors declare no conflicts of interest regarding the publication of this paper.

\section{References}

[1] Colangelo, F., Roviello, G., Ricciotti, L., Ferrándiz-Mas, V., Messina, F., Ferone, C., et al. (2018) Mechanical and Thermal Properties of Lightweight Geopolymer Composites. Cement and Concrete Composites, 86, 266-272. https://doi.org/10.1016/j.cemconcomp.2017.11.016

[2] Shivaprasad, K.N. and Das, B.B. (2018) Determination of Optimized Geopolymerization Factors on the Properties of Pelletized Fly Ash Aggregates. Construction and Building Materials, 163, 428-437. https://doi.org/10.1016/j.conbuildmat.2017.12.038

[3] Zhang, H.Y., Kodur, V., Wu, B., Yan, J. and Yuan, Z.S. (2018) Effect of Temperature on Bond Characteristics of Geopolymer Concrete. Construction and Building Materials, 163, 277-285. https://doi.org/10.1016/j.conbuildmat.2017.12.043

[4] Tuyan, M., Andiç-Çakir, Ö. and Ramyar, K. (2018) Effect of Alkali Activator Con- 
centration and Curing Condition on Strength and Microstructure of Waste Clay Brick Powder-Based Geopolymer.Composites Part B: Engineering, 135, 242-252. https://doi.org/10.1016/j.compositesb.2017.10.013

[5] Fort, J., Novotny, R., Vejmelkova, E., Trník, A., Rovnaníkova, P., Keppert, M., et al. (2019) Characterization of Geopolymers Prepared Using Powdered Brick. Journal of Materials Research and Technology, 8, 6253-6261. https://doi.org/10.1016/j.jmrt.2019.10.019

[6] Sumesh, M., Alengaram, U.J., Jumaat, M.Z., Mo, K.H. and Alnahhal, M.F. (2017) Incorporation of Nano-Materials in Cement Composite and Geopolymer Based Paste and Mortar-A Review. Construction and Building Materials, 148, 62-84. https://doi.org/10.1016/j.conbuildmat.2017.04.206

[7] Stefanidou, M., Tsardaka, E.C. and Pavlidou, E. (2016) Influence of Nano-Silica and Nano-Alumina in Lime-Pozzolan and Lime-Metakaolin Binders. Proceedings of 13 th International Conference on Nanoscience and Nanotechnologies NN16, Thessaloniki, 5-8 July 2016, 6908-6922. https://doi.org/10.1016/j.matpr.2017.07.020

[8] Mohammed, B.S. and Adamu, M. (2018) Mechanical Performance of Roller Compacted Concrete Pavement Containing Crumb Rubber and Nano Silica. Construction and Building Materials, 159, 234-251. https://doi.org/10.1016/j.conbuildmat.2017.10.098

[9] Gao, D., Chang, R., Lyu, B., Ma, J. and Duan, X. (2018) Preparation of Epoxy-Acrylate Copolymer/Nano-Silica via Pickering Emulsion Polymerization and Its Application as Printing Binder. Applied Surface Science, 435, 195-202. https://doi.org/10.1016/j.apsusc.2017.11.063

[10] Rafiee, E. and Shahebrahimi, S. (2012) Nano Silica with High Surface Area from Rice Husk as a Support for 12-Tungstophosphoric Acid: An Efficient Nano Catalyst in Some Organic Reactions. Chinese Journal of Catalysis, 33, 1326-1333. https://doi.org/10.1016/S1872-2067(11)60420-8

[11] Akram, D., Hakami, O., Sharmin, E. and Ahmad, S. (2017) Castor and Linseed Oil Polyurethane/TEOS Hybrids as Protective Coatings: A Synergistic Approach Utilising Plant Oil Polyols, a Sustainable Resource. Progress in Organic Coatings, 108, 1-14. https://doi.org/10.1016/j.porgcoat.2017.03.012

[12] Abbass, A.E., Van Vuuren, A.J., Swart, H.C. and Kroon, R.E. (2017) Distinguishing the Nature of Silver Incorporated in Sol-Gel Silica. Journal of Non-Crystalline Solids, 475, 71-75. https://doi.org/10.1016/j.jnoncrysol.2017.08.033

[13] Mahani, A.A., Motahari, S. and Mohebbi, A. (2018) Sol-Gel Derived Flexible Silica Aerogel as Selective Adsorbent for Water Decontamination from Crude Oil. Marine Pollution Bulletin, 129, 438-447. https://doi.org/10.1016/j.marpolbul.2017.10.012

[14] Khater, H.M.M. (2016) Physicomechanical Properties of Nano-Silica Effect on Geopolymer Composites. Journal of Building Materials and Structures, 3, 1-14. https://doi.org/10.12989/anr.2016.4.3.181

[15] Gao, K., Lin, K.L., Wang, D., Hwang, C.L., Tuan, B.L.A, Shiu, H.S., et al. (2013) Effect of Nano- $\mathrm{SiO}_{2}$ on the Alkali-Activated Characteristics of Metakaolin-Based Geopolymers. Construction and Building Materials, 48, 441-447. https://doi.org/10.1016/j.conbuildmat.2013.07.027

[16] Khater, H.M. (2016) Effect of Nano-Silica on Microstructure Formation of Low-Cost Geopolymer Binder. Nanocomposites, 2, 84-97.

https://doi.org/10.1080/20550324.2016.1203515

[17] Phoo-ngernkham, T., Chindaprasirt, P., Sata, V., Hanjitsuwan, S. and Hatanaka, S. 
(2014) The Effect of Adding Nano- $\mathrm{SiO}_{2}$ and Nano- $\mathrm{Al}_{2} \mathrm{O}_{3}$ on Properties of High Calcium Fly Ash Geopolymer Cured at Ambient Temperature. Material and Design, 55, 58-65. https://doi.org/10.1016/j.matdes.2013.09.049

[18] El Mir, L. (2017) Luminescence Properties of Calcium Doped Zinc Oxide Nanoparticles. Journal of Luminescence, 186, 98-102. https://doi.org/10.1016/j.jlumin.2017.02.029

[19] ASTM, D1633-00 (2007) Standard Test Methods Compressive Strength Molded Soil-Cement Cylinder. ASTM International, Pennsylvania.

[20] Lo, K.W., Lin, K.L., Cheng, T.W., Chang, Y.M. and Lan, J.Y. (2017) Effect of Nano- $\mathrm{SiO}_{2}$ on the Alkali-Activated Characteristics of Spent Catalyst Metakaolin-Based Geopolymers. Construction and Building Materials, 143, 455-463.

https://doi.org/10.1016/j.conbuildmat.2017.03.152

[21] Deb, P.S., Sarker, P.K. and Barbhuiya, S. (2015) Effects of Nano-Silica on the Strength Development of Geopolymer Cured at Room Temperature. Construction and Building Materials, 101, 675-683.

https://doi.org/10.1016/j.conbuildmat.2015.10.044

[22] Assaedi, H., Shaikh, F.U.A. and Low, I.M. (2016) Influence of Mixing Methods of Nano Silica on the Microstructural and Mechanical Properties of Flax Fabric Reinforced Geopolymer Composites. Construction and Building Materials, 123, 541-552. https://doi.org/10.1016/j.conbuildmat.2016.07.049

[23] Aughenbaugh, K.L., Williamson, T. and Juenger, M.C.G. (2015) Critical Evaluation of Strength Prediction Methods for Alkali-Activated Fly Ash. Materials and Structures, 48, 607-620. https://doi.org/10.1617/s11527-014-0496-Z

[24] Raphaëlle, P. (2015) Formulation and Durability of Metakaolin-Based Geopolymers. PhD Thesis, Toulouse III University, Toulouse.

[25] Chindaprasirt, P., De Silva, P., Sagoe-Crentsil, K. and Hanjitsuwan, S. (2012) Effect of $\mathrm{SiO}_{2}$ and $\mathrm{Al}_{2} \mathrm{O}_{3}$ on the Setting and Hardening of High Calcium Fly Ash-Based Geopolymer Systems. Journal of Materials Science, 47, 4876-4883. https://doi.org/10.1007/s10853-012-6353-y

[26] Dahm, D.J. and Dahm, K.D. (1999) Representative Layer Theory for Diffuse Reflectance. Applied Spectroscopy, 53, 647-654. https://doi.org/10.1366/0003702991947298 https://www.osapublishing.org/as/abstract.cfm?URI=as-53-6-647

[27] Gasca-Tirado, J.R., Manzano, A., Villaseñor, C., Muñiz-Villarreal, M.S., Zaldivar-Cadena, A.A., Rubio-Ávalos, J.C., et al. (2012) Incorporation of Photoactive $\mathrm{TiO}_{2}$ in an Aluminosilicate Inorganic Polymer by Ion Exchange. Microporous and Mesoporous Materials, 153, 282-287.

https://doi.org/10.1016/j.micromeso.2011.11.026

[28] Gasca-Tirado, R., Rubio-Ávalos, J.C., Muñiz-Villarreal, M.S., Manzano, A., Reyes-Araiza, J.L., Sampieri-Bulbarela, S., et al. (2011) Effect of Porosity on the Absorbed, Reemitted and Transmitted Light by a Geopolymer Metakaolin Base. Materials Letters, 65, 880-883. https://doi.org/10.1016/j.matlet.2010.12.003

[29] Muñiz-Villarreal, M.S., Manzano, A., Sampieri-Bulbarela, S., Gasca-Tirado, J.R., Reyes-Araiza, J.L., Rubio-Avalos, J.C., et al. (2011) The Effect of Temperature on the Geopolymerization Process of a Metakaolin-Based Geopolymer. Materials Letters, 65, 995-998. https://doi.org/10.1016/j.matlet.2010.12.049

[30] Adak, D., Sarkar, M. and Mandal, S. (2014) Effect of Nano-Silica on Strength and Durability of Fly Ash Based Geopolymer Mortar. Construction and Building Mate- 
rials, 70, 453-459. https://doi.org/10.1016/j.conbuildmat.2014.07.093

[31] Zaharaki, D., Komnitsas, K. and Perdikatsis, V. (2010) Use of Analytical Techniques for Identification of Inorganic Polymer Gel Composition. Journal of Material Science, 45, 2715-2724. https://doi.org/10.1007/s10853-010-4257-2 